\title{
Development of the under-channel space of the center of Moscow: reducing regulatory risks
}

\author{
Valery Belyaev ${ }^{1, *}$ \\ ${ }^{1}$ Moscow University of Civil Engineering, Yaroslavskoe shosse, 26, Moscow, 129337, Russia
}

\begin{abstract}
The current situation, environmental and other main problems of territorial development of the central historical part of the city of Moscow are considered. In the context of national peculiarities of legal and technical regulation, conceptual proposals for the development of the subsurface space of the Drainage channel are analyzed. The purpose of the analysis was to assess compliance with world practice, the General Plan of the city, other documents and documentation of urban planning design, as well as the main legal norms and documents on standardization (Code of Rules "Buildings, structures and complexes underground. Rules of urban planning design"). The analysis was carried out taking into account the areas of improvement of legal and technical regulation. It is concluded that the considered variant of spatial development has a fundamentally new, innovative character and can give significant environmental and social effects. At the same time, the results of the analytical stage showed the need to supplement the General Plan of the city in the considered part. The presence of regulatory risks is also revealed, their causes are identified and some general suggestions for reducing such risks are given. The above analysis and recommendations can be useful for representatives of the authorized state authorities of the city of Moscow, for the customer (investor, developer) and the executor of the further implementation of the considered project, as well as for representatives of the expert community.
\end{abstract}

\section{Introduction}

The direction of development of urban underground space (hereinafter also - UUS) is becoming a trend for many large and largest cities in the world. It continues to be documented as one of the key themes of the strategic development of the capital of the Russian Federation, which is recorded, for example, in the General Plan of the City of Moscow [1], in the City Program of Urban Planning Policy [2] and was mainly associated with the shortage of urban land.

With the implementation in 2012 of the decision to annex new territories to the city, which exceed the previous area of the city's territory by almost 1.5 times, there is a noticeable decrease in public authorities' interest in the topic of UUS development (in our opinion, this decision itself was purely administrative in nature, was not provided with sufficient legal and urban planning justification and did not meet the modern urban model

\footnotetext{
${ }^{*}$ Corresponding author: Vbelyaev2011@mail.ru
} 
of a compact city). At the same time, for the central zone of the city, the problem of the shortage of territorial urban planning resources has not only persisted, but also worsened. This is due, for example, to the launch of a large-scale program of renovation of residential areas of the city, the streamlining and tightening of federal legislation in the field of establishing prohibitions and restrictions in historical zones of protection of cultural heritage and in the field of environmental protection. Despite the higher overall (compared to other districts of Moscow) indicators of provision of transport and social infrastructure facilities, in the central zone of the capital, for example, there is a clear lack of parking and public space, including green areas. The tourism infrastructure is not sufficiently developed. Even with a significant increase in the volume of construction of transport infrastructure facilities and after the introduction of parking fees, the center of Moscow is overloaded with traffic flows (Fig. 1). All this negatively affects the environmental situation, requires measures to reduce harmful emissions, noise, etc. The high density of development, the noted prohibitions and restrictions indicate the exhaustion of the possibility of traditional extensive construction to eliminate regulatory gaps in security. In this regard, as world practice shows, the problem can be solved by developing UUS (cities in Western Europe, Canada, etc.).

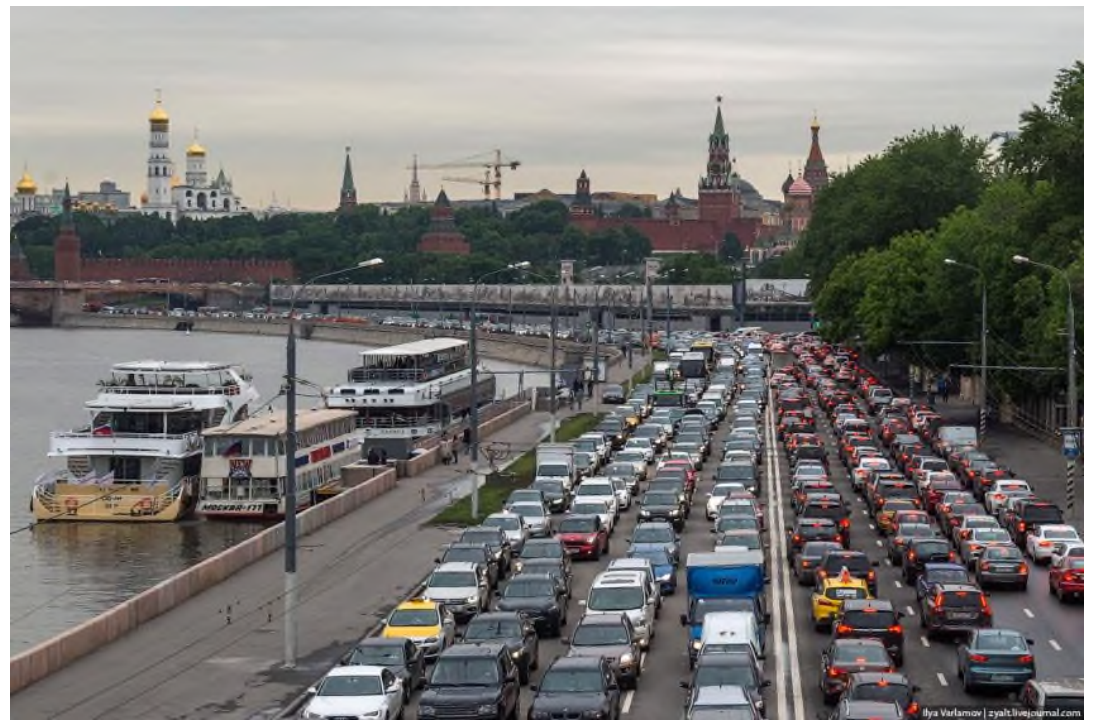

Fig. 1. Total traffic jams on the Kremlin embankment (photo from Wikipedia materials).

Following the modern principles of the global target urban agenda, the Priority project "Formation of a comfortable urban environment" is being implemented in Russia (http://government.ru/projects/selection/649/25517/) and developed a methodology for calculating the urban environment quality index (http://government.ru/docs/36153/.). In turn, at the regional level, for example, the program of the City of Moscow "Development of the urban environment" was adopted (https://budget.mos.ru/gp_rest). In particular, it notes the lack of active promotion of the city of Moscow as a cultural and tourist center, the need for a comprehensive systematic approach to the development of the urban environment, the effective use of natural resources while developing the relevant facilities and infrastructure. And first of all it concerns the central zone of the capital.

As in other major cities of the world, the development of UUS, of course, should be considered as an effective way to increase the level of environmental friendliness and comfort of the urban environment of the capital. On the one hand, it allows you to create reserves of land for its modern and environmentally oriented target use (pedestrians, 
cyclists, green areas, etc.). On the other hand, there is an additional opportunity to create the necessary services and infrastructure underground, which, as already mentioned, is most relevant for the historical territories of cities.

In this regard, as part of [2], a subprogram for the development and reorganization of the center and other territories of the city of Moscow has been allocated and is being implemented. In particular, it provides for the coordination of works on the complex arrangement and development of the central part of the city of Moscow, carried out by the Department of Urban Planning Policy of the city of Moscow. There are also a number of specific measures for the development of the UUS, including the need to "adapt water bodies to provide recreation for residents and guests of the city".

In turn, we believe that water bodies can be adapted not only for these purposes, but also for other purposes by the appropriate development of the underground (under-channel) space. This is confirmed, among other things, by some examples of world practice, discussed below. In relation to the central part of Moscow, such attempts were also made. So in 2013, the specified Department carried out competitive procedures for 15 pallet parking lots in the bed of the Moscow River. A number of reputable foreign design and construction companies and investors showed real interest in their creation. Despite this and the innovative nature of the draft proposals, the competition was not held mainly due to the position of the authorities in the field of water resources (fears of threats to the systemic flow of the river, navigation, etc.). Although it should be noted that as part of the new urban planning policy of the city of Moscow, it is the water area of the Moskva River that is considered not only as the main planning axis, but also as a priority area for finding new urban planning solutions for historical riverside zones (.https://my-river.ru/about.html).

The level of such risks is significantly lower when considering another water body - the territory of a Drainage channel-as an object of development (reconstruction). Therefore, in the early 2000s, a project was developed for an underground two-level parking lot for 860 cars under the section of the Drainage Channel from the monument to Peter I to the Maly Kammenny Bridge. Unfortunately, it was not implemented for economic and other reasons.

It should be noted that in line with the new urban planning policy of the city of Moscow, it is the water area of the Moskva River that is considered not only as the main planning axis, but also as a priority area for finding new urban planning solutions for historical riverside zones (.https://my-river.ru/about.html). In this regard, the proposal of the Research Institute of based and underground structures named after Gersevanov (NIIOSP) (hereinafter also - NIIOSP) for the reconstruction of the entire territory of the Drainage Channel is more interesting and large-scale, but at the same time, in our opinion, complex, even somewhat problematic [3,4]. Therefore, it was the subject of the study, the results of which are reflected in this article. The purpose of the study was to further substantiate the possibility and feasibility of developing the sub-urban space of the central territory of the largest cities of Russia (on the example of the city of Moscow) as a new direction of sustainable spatial development, as well as identifying ways to reduce the risks that arise in the field of legal and technical regulation. Similar studies in relation to the urban development of the development of sub-urban space have not been conducted in Russia before. The use of individual works by foreign authors is problematic due to the national Russian specifics of the system of legal and technical regulation of the development of UUS [5].

\section{Materials and methods}

Assessment of the situation and problems in the field of underground development of watered (under-channel) urban areas and the real possibilities of using this method of spatial development is considered on the example of the territory of the Drainage channel in 
the center of Moscow. The history of the issue and individual examples-analogues of world practice are considered. In the context of innovations in standardization and trends in legal regulation, the assessment of compliance of NIIOSP pre-project proposals with the norms of federal legislation (urban planning, water, land, etc.) and the requirements of the main regulatory technical documents was carried out. According to the results of the analytical assessment, the relevant proposals for the underground development of the territory of the Drainage channel zone are given. It also considered the practice of expertise of the author of this article as an Advisor on the development of UUS of the head of Department of urban planning policy of Moscow (volunteer) and as scientific Secretary of the Section "Urban design and underground urbanism", United scientific and technical Council of the Urban complex of the city of Moscow. Also analyzed are the possibilities of applying the requirements of the new set of rules 473.1325800.2019 "Buildings, structures and complexes underground. Rules of urban planning design" (hereinafter-SP 473), introduced in the summer of 2020 .

\section{Results and discussion}

The drainage canal was laid at the end of the 18th century along the central radiation of the Moskva River near the Moscow Kremlin, thus forming the Balchug Island together with the Moskva River. The canal originates above the Bolshoy Kamenny Bridge, near the monument to Peter I, and flows into the river near the Shluzovaya embankment (Fig. 2). The canal is $4 \mathrm{~km}$ long, 30 to $50 \mathrm{~m}$ wide, and about $2 \mathrm{~m}$ deep. 11 bridges have been thrown across the canal, including 5 pedestrian bridges. The canal was laid along a swampy lowland (the old channel of the Moskva River). At the same time, the swamp was drained, in addition, the channel was supposed to protect the floodplain areas from floods. In the 20th century, after the reconstruction of the structures of the Moscow river basin, it lost its drainage and navigational importance. Today the Vodootvodny Canal is included in the list of inland waterways of federal or regional significance. Moving and small vessels on it are carried out chaotically without passenger state supervision over the safety of navigation. Work on waterways and activities for navigation and hydrographic support are not being carried out.

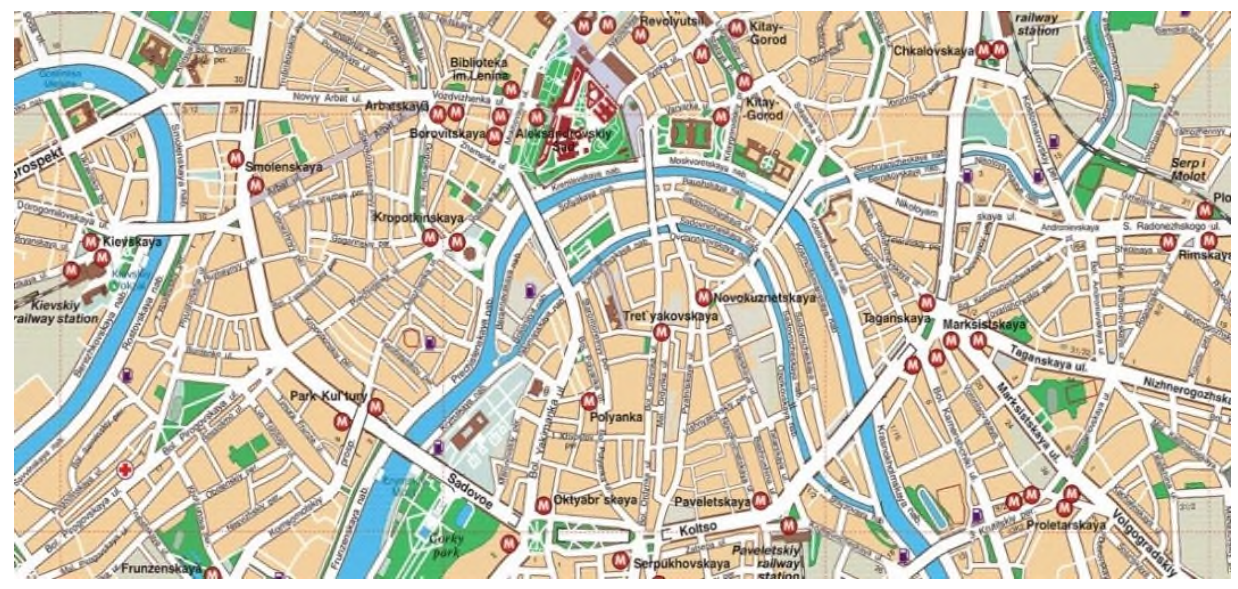

Fig. 2. Dislocation of the water drainage channel on the map of Moscow (http://tvosibgtv.ru/events_geotechnics/koncepciya-reorganizacii-rusla-vodootvodnogo-kanala-gmoskvy.html). 
With this in mind and taking into account the above-mentioned preconditions underground spatial development of the city centre of Moscow, as well as some examples of best practice and innovation in the field of construction and geotechnical technology specialists, NIIOSP, as already mentioned above, was the initiative developed a conceptual proposals for the use of UUS in the waters of Russian cities for example the reorganization of a channel of a Drainage channel in Moscow (hereinafter - the Draft concept) [3, 4].

The idea is that over the entire area of the canal, its bottom is sunk 10-18 m to create an underground two-to five-level multi-purpose structure (hereinafter also referred to as the Complex). Its underground part is structurally an extended "box" foundation for the installation of various buildings, overpasses and other structures. At the same time, the channel mirror can be preserved for practical (hydrotechnical, small navigation) and aesthetic purposes, both completely and partially (Fig. 3).

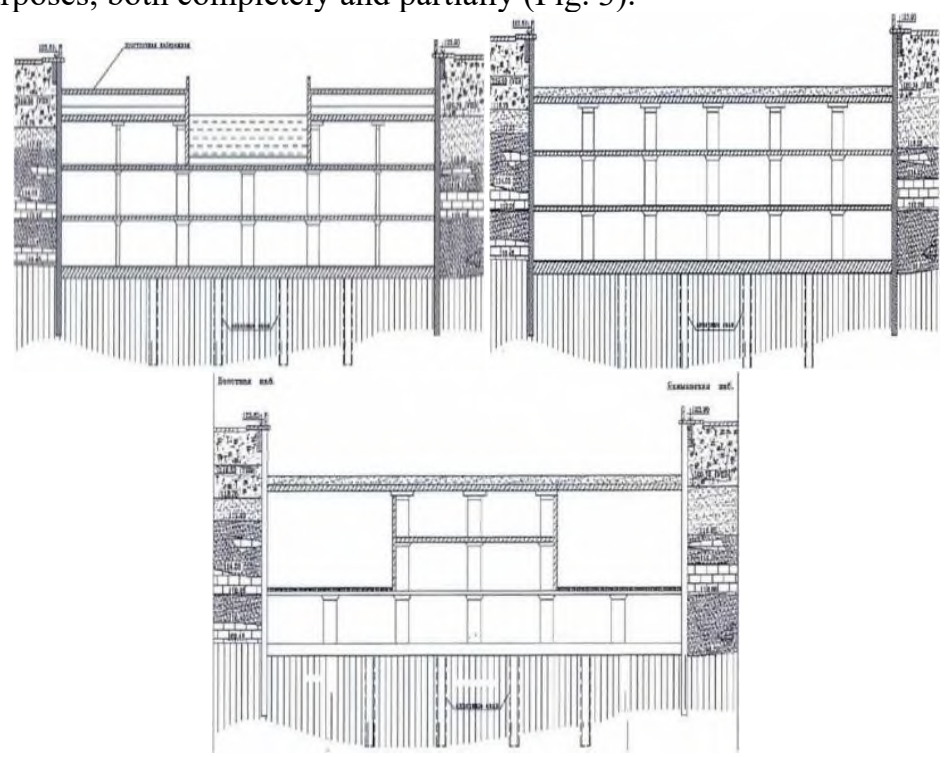

Fig. 3. Variants of the cross-section of the Complex (NIIOSP proposals $[3,4]$ ).

The aboveground part of the water area of the canal and adjacent embankments is proposed to be divided thematically into 4 historical zones, symbolizing various epochs of Russian history from the end of the XVII century (from Peter I) to the present day. Accordingly, the theme of the zone should determine its design and a set of types of structures. Underground or underground-aboveground multi-level parking lots, exhibition halls and cinemas, winter gardens, gyms, oceanariums, etc. are being built on the drained (temporarily or permanently, completely or partially) territory of the canal bed. Section of the Complex may be allocated for transit or special passenger transport (far right option in Fig. 3). The transverse dimension of the Complex is $40-50 \mathrm{~m}$, which essentially corresponds to the width of the existing channel. At the same time, the possibility of setting up local (up to $100 \mathrm{~m}$ ) extensions ("pockets") and exits to them from adjacent streets is considered. The complex can be connected to the underground lines running below.

Recently, the idea has been transformed on a large scale: as a radical option, it is proposed to consider the Draft Concept as part of a mega-project to create the largest tourist, social and educational project in Russia - the "Park of Russia" (http://tvosibgtv.ru/events_geotechnics/koncepciya-reorganizacii-rusla-vodootvodnogo-

kanala-g-moskvy.html). Such a park is proposed to be created by combining newly created pedestrian zones with adjacent embankments. This will form a single pedestrian embankment, the longest in the country and the second in the world in its length. This area 
is supposed to be equipped with parks, innovative shopping areas, technopolises, exhibition halls, cinemas, winter gardens, gyms, etc. Along the entire length of the park, a network of cross-country and bicycle paths is proposed, which in winter it is advisable to use for creating ski and skating trails.

The very design of the Complex is proposed to Supplement option possible strip objects of high-speed rail or aquatonale in the third underground level, which will allow "to close" Boulevard ring of the capital. However, in our opinion, such a "closure" will be of a nominal nature, if we do not consider the possibility of creating green underground areas of the territory, while applying innovative technologies for transmitting daylight underground, recommended by the author of this article (https://www.elibrary.ru/item.asp?id=43283557).

On both sides of the channel, it is also proposed to lay two main "pass-through" collectors with a cross-section of up to $5 \times 4 \mathrm{~m}$ for joint laying of engineering communications in them. Despite the identified individual shortcomings of the technical regulation of the implementation of such laying (https://www.elibrary.ru/item.asp?id=37165500), such a decision is certainly to be welcomed.

According to preliminary estimates of the authors of the Draft Concept, the implementation of such a project will allow for at least half a million $\mathrm{m} 2$ of additional space. When implementing a radical approach, the newly created total area of halls, driveways and parks can be at least twice as high. It is also planned to place about 7,000 parking spaces in underground car parks, which should be sold or rented out.

But most importantly, in our view, what is the result on the territory of the waters of the Drainage channel and its embankments is arranged in a unique, harmonious place of citizens and tourists (Fig. 4). No noisy traffic, increasing of green space and saving water will significantly improve the environmental situation in the Central part of the city of Moscow.

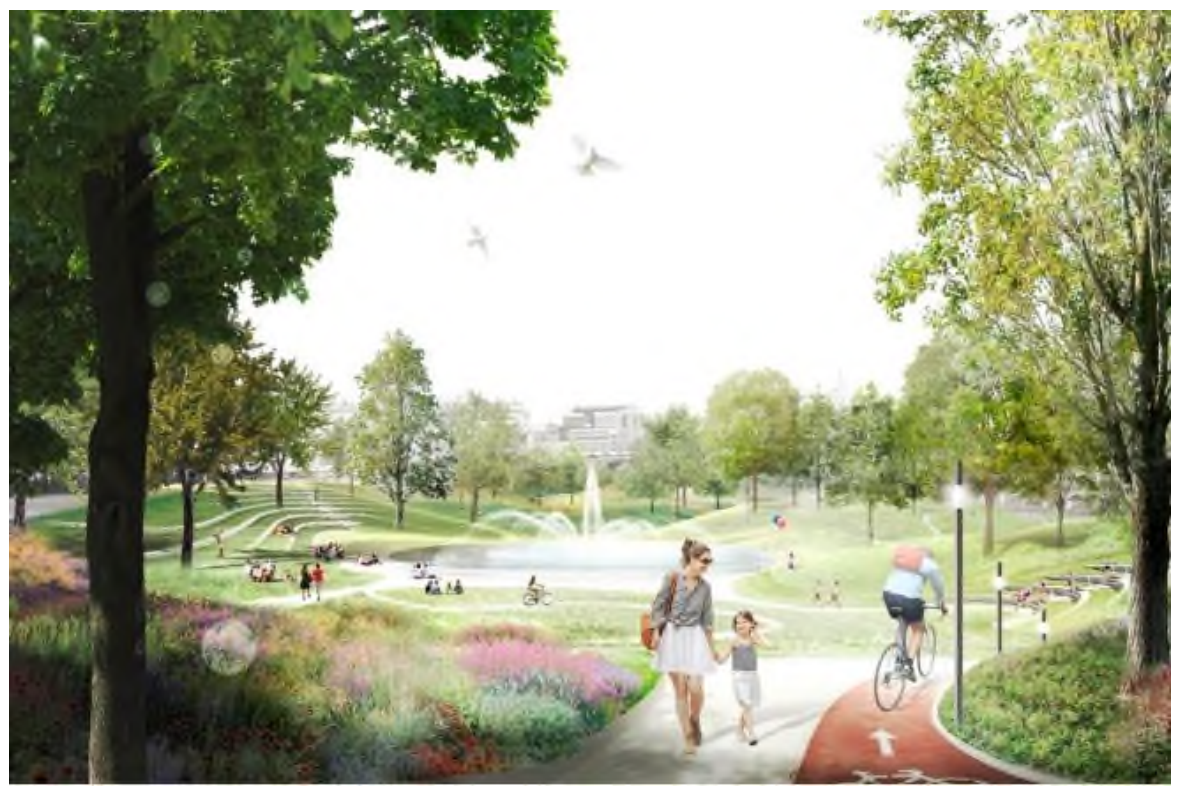

Fig. 4. Improvement proposal for the section of partial filling of the Drainage channel bed (Architectural Bureau «Tsimailo Lyashenko and Partners»).

Due to the high responsibility of the location of the canal itself, the scale and innovative nature of the proposals for the reconstruction of its territory, it is advisable to analyze in 
more detail the main aspects of the Project concept and the possibility of practical implementation of this, of course, interesting, but at the same time quite radical idea.

First of all, it is extremely important to find the right foreign analogues and study them in detail. When preparing the Draft Concept, some examples of the use of underground space in water areas were considered, which, strictly speaking, are not direct and modern analogues. This is how the recreational and entertainment zone in the city of Valencia (Spain) is considered. However, it was created in the 60s of the last century, and on the site of the already allocated riverbed outside the city. The transport tunnel between the cities of Copenhagen (Denmark) and Malmo (Sweden) is not an urban structure and is laid on the sea, not on the river bottom. The main station of the city of Berlin (Germany) with underground tiers is not in itself a linear structure.

At the same time, unfortunately, the closest and most relevant foreign counterpart - the project AMFORA (Alternative Multifunctionele Ondergrondse Ruimte Amsterdam), awarded in 2010 with the international award in the field of development and architecture MIPIM Future Projects 2010, has not been considered. The analogy in this case is direct-it is planned to build a complex of underground structures under the canals and under the Amstel River in the central historical part of the capital of the Netherlands, Amsterdam (https://www.zja.nl/nl/page/2819/amfora-amstel-amsterdam). It is important that the project was a response to the municipal action plan "Healthy City 2008-2014", contributing to the solution of the most urgent problems of city development and environmental improvement.

The AMFORA project is a radical solution for the development of urban space, increasing its sustainability and comfort of the living environment (freeing up valuable city center land for modern public use as an alternative to its scarcity and not always orderly use). The design solution of the AMFORA project is to create an underground 6-storey structure (in fact, a building) with a length of about 500 meters in the channel of the water body. Its upper 3 levels are used for a wide variety of shopping, entertainment and public functions, while the remaining levels are occupied by parking lots, warehouses, and locations of infrastructure facilities.

The project is characterized by an integrated approach to the use of UUS services and its environmental orientation. So, along with the utilitarian, proper spatial context (the creation of a multifunctional arrangement of the UUS), the geo-energy potential of the UUS is also used (effective solutions for obtaining heat pump energy and using its excess on the territory of neighbouring city blocks). It is important that after the creation of underground floors, the channel of each channel is recreated. It provides a unique system of ventilation, exhaust gas filtration, navigation, lighting, colour design, etc. Spatial integration is provided by special planning and design solutions for transport and other connections with ground objects. Construction and geotechnical innovations are proposed (temporary drainage of canal sections, modern methods of creating underground floors, soil freezing, etc.).

Of course, the implementation of the AMFORA project requires significant efforts and investments in the amount of several billion euros. According to experts, it will take at least 10 years. However, taking into account the creation of additional areas (at least 1 million $\mathrm{m} 2$ ) and the high cost of land in the centre of Amsterdam, the project is attractive for private investors and is commercial in nature (in this regard, a separate study of the proposed public-private partnership model for the purposes of its possible use in the development of the territory of the city of Moscow). The first step in the implementation of the project can be considered the creation of a two-level parking garage (Albert Cuyp parking garage) under one of the sections of canals in the city of Amsterdam. The object is the winner of the Architizer A+Awards 2019 in the category Architecture + Urban Transformation, which also confirms the fundamental effectiveness of the considered method of development of the UUS riverbed of urban reservoirs. 


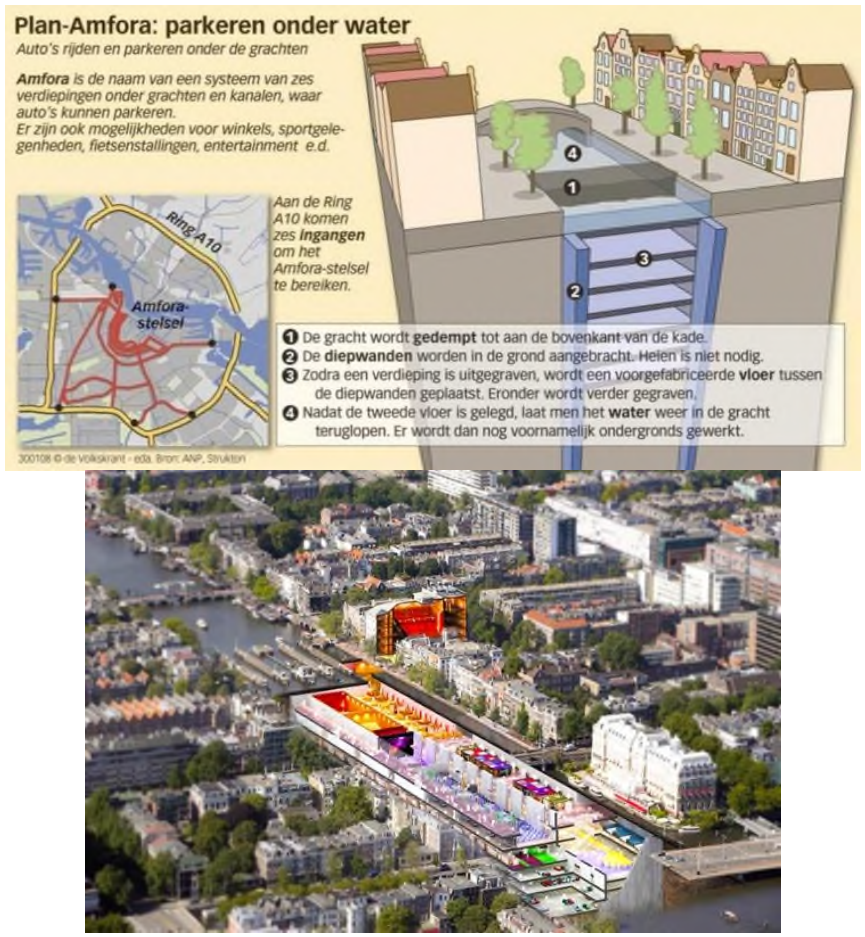

Fig. 5. AMFORA project for underground development of water bodies in the city of Amsterdam (source: Zwarts \& Jansma).

In a sense, an example of the reconstruction of canals in another city of the Netherlands - in Utrecht, where cafes, pubs, souvenir shops and other objects have been created under the embankments. Moreover, their entrances and exits are oriented to the canal with the creation of public spaces for recreation directly by the water (https://www.theguardian.com/world/2020/sep/14/utrecht-restores-historic-canal-madeinto-motorway-in-1970s). Another indirect analogue is the large-scale reconstruction of the area near the streambed in the centre of Seoul, with the reconstruction of the streambed and the organization of a linear public recreation space with a length of 11 kilometers (Fig.6).

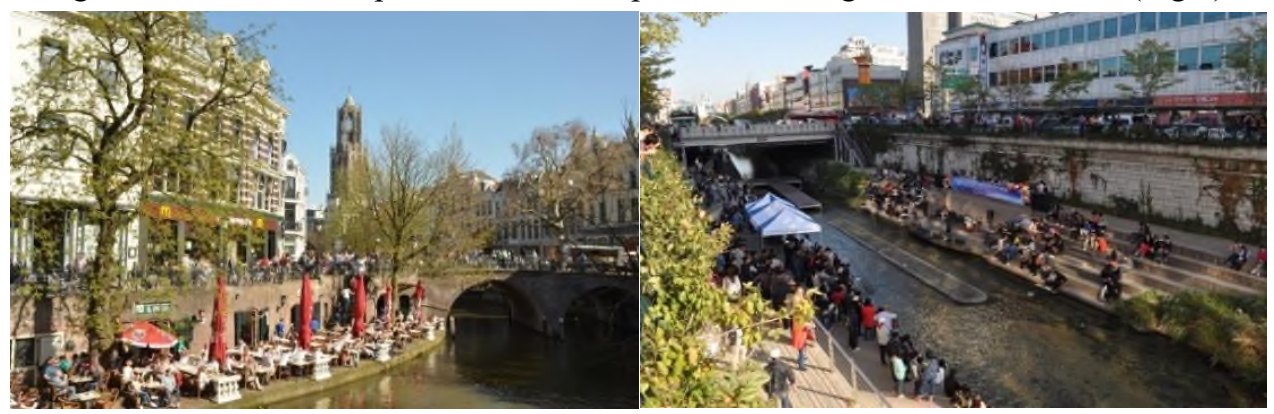

Fig. 6. Summer terraces on the canals of the city of Utrecht (photo: www.needpix.com) and a stream in the city of Seoul (https://commons.wikimedia.org/w/index.php?curid=32556903).

The fundamental principle and requirement of the legislation on urban development is the implementation of any construction on the basis of territorial planning documents, land use and development rules and documentation on the planning of the territory (Articles 2, 9, 
etc. Code [6]). It can be assumed that in relation to the case under consideration, this means that, first of all, the placement and creation of such a large-scale multifunctional object should be provided for as part of the General Plan of the city of Moscow. The need for this is confirmed below by the results of the analysis of the relevant norms of the federal and Moscow urban planning legislation. Similar requirements are set out in the main documents on standardization. In particular, the General Provisions of SP 473 indicate that the planning and development of UUS should be reflected in master plans, territory planning projects and programs for the integrated development of municipal and (or) transport infrastructure systems (such infrastructure development programs in the city of Moscow, unfortunately, have not yet been developed). In turn, when developing master plans and planning projects, the development of UUS should be designed based on an assessment of the economic-geographical, social, industrial, historical-architectural and natural-resource potential of the development of territories (paragraph 4.7 of SP 473). Note that so far these and many other requirements of SP 473 are not fully supported by the necessary development of federal legislation. However, such work is actively carried out on the initiative and with the participation of the author of this article. Specific proposals for amendments and additions to a number of federal codes and laws, including those related to urban planning, land and subsoil use, have already been substantiated and prepared [5].

First of all, be aware that a number of facilities proposed for placement in the Complex under the town planning legislation of Moscow city related to the status of objects of townplanning activities of regional significance. At the same time, it is the task of locating these objects first addressed in the General plan of the city of Moscow, and solved it with the use of urban design regulations, which are then to be applied also in preparation of documents, zoning and urban planning documentation on territory planning [6,7].

If we talk about capital construction projects, then among them the status of objects of regional significance is in fact the majority of objects from among the proposed for placement as part of the Complex. These are objects of culture, leisure, physical culture and sports, transport infrastructure, including linear objects of the street and road network, parking lots, parking lots, garages (for use by an unlimited number of persons), objects of engineering infrastructure and municipal utilities, including linear objects. In addition, such status is given to public areas (for example, squares proposed for creation on certain sections of the Complex) and the zones themselves of the planned placement of capital construction projects of regional significance. [6]

Further confirmation of the assumptions is that the limit values of the availability and provision of such facilities (e.g. car parks) at their placement already established by the Government of Moscow in the framework standards for urban design [8].

According to the Moscow urban planning legislation, the placement of some of the above-mentioned objects should be detailed as part of the so-called territorial and sectoral schemes. They are developed in the development of the master plan for the entire city, or part of it (the format of such documents (schemas) is not provided by the Federal Urban development Code and in this respect they status is not quite legitimate, see also below about the features of the Moscow town-planning legislation). Among them are a number of narrow-industry schemes for the placement of objects of the recreation industry, tourism and public catering, parking lots, bike paths, berthing facilities, urban engineering sewers, public toilets). The placement of objects of the projected Complex can also be further harmonized when developing industry-specific schemes for the development and placement of recreation areas in the city of Moscow in water protection zones of water bodies, tourist and recreational zones, natural and green areas.

At the same time, when analyzing the materials of the General Plan and industry schemes, it was found that their materials do not provide for the placement (creation, reconstruction) of either the Complex itself or any objects of regional significance from its 
composition. Therefore, in this part, for formal reasons, it is necessary to ensure that changes are made to the General Plan of the city (for the option of reconstructing the Drainage Channel as a linear object, see below).

In addition, it was found out that the requirement of urban planning legislation that any development of the territory should correspond to the nature of the purpose of the corresponding functional zone and the parameters of development of its territory established by the Master Plan may not be fulfilled. Namely the development area at the water surface, within which it is proposed the creation of the Complex is not planned as the main parameter of development (planned total area of underground and ground buildings) has a value of zero. In our opinion, this circumstance is a significant flaw in the Master Plan, especially since it was developed at a time when large-scale annexation of new territories to the city did not occur, that is, in conditions of a severe shortage of land suitable for development. The establishment of such a parameter, of course, is a progressive step that meets the best world practice. We can only regret that due to the weak methodological elaboration of the issue and the lack of sufficient statistical data, the authors of the document (the Master Plan has the force of the Law of the City of Moscow [1]) failed to isolate the underground component in this parameter.

Another important legislative requirement is that changes and additions to the master plan are made in the same order as the preparation of the master plan was carried out [6]. This means that, first of all, the proposed development of the canal territory should be reflected as a goal setting in the strategic planning documents of the city of Moscow (strategies, programs). However, unfortunately, they are still very poorly focused on the development of urban underground space and of course do not contain provisions on the development of the territory under consideration [5]. In addition, the entire multi-stage procedure for preparing and approving the master plan must be maintained (the decision of the Moscow Government to prepare proposals for making changes to the master plan, conducting competitive procedures for public procurement, performing engineering surveys and preparing design and planning solutions with access to them, conducting public discussions or public hearings on the project of making changes to the master plan, taking into account the proposals of interested parties, necessary approvals, consideration and approval of amendments by the Moscow City Duma, etc.). Despite the conceptual nature of the mentioned requirement, the Federal Ministry of Construction proposes to reduce its rigidity, delineate and unload the procedure for making changes to the general plans of cities, including using the new format of the master plan for Russia (https://tass.ru/nedvizhimost/7851721). In our opinion, the prospect of such "optimization" is possible only if it is systematically scientifically justified and the interaction with the Federal Ministry of Economic Development, which is responsible for territorial and strategic planning, is harmonized.

An integral and extremely important part of the general plan of any city is the materials for its justification. In our case, following the legal requirements (part 7 of Article 23 of the Code [6]) and technological logic, the rationale for the chosen location of the abovementioned objects of regional significance should first be prepared with an assessment of their possible impact "on the integrated development of these territories", possible directions for the development of the territory under consideration and projected restrictions on its use, as well as with an assessment of the main risk factors for natural and man-made emergencies.

It should be recognized that due to various reasons (the desire to save budget funds, the lack of requirements for approval and approval of materials for justification, insufficient methodological support for their preparation, etc.) in practice, this stage of territorial planning is not given due attention. A similar situation is observed in relation to the preparation of materials for the justification of documentation on the planning of the 
territory at the next stage. All this, of course, does not contribute to making better planning decisions.

A feature of the urban planning legislation of the city of Moscow is far from full compliance with federal legislation. Due to the general constitutional requirements and article 4 of the Code [6], such a discrepancy is considered unacceptable, therefore, in particular, it is actively criticized by the authors of the Code. Thus, as an element of "manual" regulation, the creation and excessively broad powers of city and district commissions on urban planning, land use and development (urban planning and land commissions) are noted [9].

In particular, the powers of the city commission include consideration of pre-project evaluation materials of "urban development potential". Moreover, their approval by the commission is considered not only the basis for making changes and additions to the Rules of Land Use and Development of the city, but it is also proposed to consider it as a decision on the need to prepare an appropriate project for planning the territory. [10]. It has chosen this path at present, the initiators of the Project concept and potential investors, ordering the developer of the General plan of Moscow, the execution of works on assessment of capabilities and urban conditions of use underflow space Drainage channel (the format of the contract to perform this work in our view requires clarification, he at least has a hybrid nature, including elements of contract for design and survey works, and also contracts for research work). Meanwhile, it should be noted that this practice is not fixed by the legislative norm of the city of Moscow, as required by Part 19 of Article 45 of the Federal Code [6]. No one has cancelled another, procedural rule of part 10 of Article 45 of this Code that the preparation of documentation on the planning of the territory, in particular in the city of Moscow, should be carried out on the basis of the General Plan of the city. These circumstances indicate the existence of a legal risk of the proposed solution.

However, it should be recognized that in reality the level of such risk in current practice is levelled taking into account larger-scale precedents. For example, the above-mentioned annexation of new territories of the capital, contrary to legislative requirements [6], did not end with the introduction of the necessary changes and additions to the General Plan of Moscow, moreover, it was not based on any of the territorial planning documents.

There is also a tendency to "blur" the conceptual norms of the federal Code, and largely under the reverse influence of the urban planning legislation of the city of Moscow. In particular, the elements of recreating the model of "special regulation" of urban development are noticeable (the attached territories of " New "Moscow, the zones of renovation of residential buildings, the practice of "lowering " the legal status of land use and development rules, etc.). This is also confirmed by the nature of the recent amendments to the federal law on the status of the capital of the Russian Federation. As part of the expanded powers to "establish the specifics of urban planning activities in the city of Moscow", the city's state authorities can now, in coordination with the Government of the Russian Federation, establish the specifics of the composition, content, procedure for developing and approving the city's master plan, and the specifics of the procedure for making changes to the master plan. If necessary, they can also determine the list of information, documents, and materials required for this purpose (similar new powers also apply to the rules of land use and development of the city and documentation on the planning of the territory). In addition, it should be recognized that the risk of the need to make changes and additions to the General Plan of the city for the case under consideration may reduce the fact of an insufficiently clear regulatory definition of the term "reconstruction of linear objects" and more lenient norms of the current Code for planning such reconstruction [6].

However, in any case, when performing the necessary sections of the evaluation work, a number of important circumstances should be taken into account. Thus, when analyzing the 
current situation and identifying the prerequisites for the development of the canal territory, it is necessary to understand how the Draft Concept relates to the planned development of adjacent territories, taking into account the existing planning studies. First of all, this concerns the prospects for urban development of the territories adjacent to the Moscow River. They were determined by holding an international competition, which resulted in finalizing the concept of urban development of coastal areas with a perspective until 2035 and, in fact, forming a program for such development. Despite the fact that we are talking about the implementation of a mega-project to create a unified linear city centre with high quality urban environment, public spaces and landscaping, the analysis of the materials showed almost complete disregard for the possibility of using urban potential underflow space rivers (the Moskva river, Yauza), and a Drainage channel. This, in our opinion, indicates both the lack of real interest in this city customer, and the lack of professional qualifications of both the customer and planners. It should be noted that some steps in the direction of training and advanced training of personnel are carried out by the author of this article on an initiative basis (including the relevant requirements in the updated standard of professional activity "Urban Planner", the development of higher education in the direction of "Underground Urbanism").

At the end of 2016, the Moscow Government appointed one of its specialized institutions (State Research and Design Institute for Urban Development of the City of Moscow) as a single urban operator for the implementation of the concept of urban development of the territories adjacent to the Moscow River. Also, it was entrusted with the authority of general coordination of development projects of this territory, which implies the need to coordinate the Draft Concept and steps for its implementation with the specified Institute.

The most important urban planning factor to be taken into account is the prospect of development of the territory of Balchug Island, formed by the Moscow River and Drainage Channel (often called the Golden Island due to its unique location (next to the Moscow Kremlin) and the corresponding maximum price of land and other real estate). In recent decades, the planning concepts of reconstruction and development of the island's territory have changed following the change of the city's leadership and the change in the direction of the city's urban planning policy. Accordingly, the composition of developers changed. Today, it was decided that a new elite residential cluster is being formed in the central part of the island as part of two large exclusive projects (complexes) with new housing formats for the capital and the highest level of service and privacy. Despite the absence of an approved territory planning project (such a project was developed for another, insignificant part of the territory of the quarters [16] 360, 361 of the Yakimanka district), construction is already underway. In addition, urban planning plans of land plots were issued as initial data for the design of a number of other objects in other parts of the island, as well as in the territory adjacent to the Drainage Channel from the south.

If we talk about urban zoning, this institution in Russia is still at the stage of its development. Unlike some other countries, it is not yet adapted to regulate the creation of underground real estate objects (some prospects in this regard are being worked out within the framework of the above-mentioned justification for the development of federal legislation). In addition, according to [6], zonal regulation is not applied in the case of a watered public area, the development of which is proposed to be carried out by creating a Complex as a linear object. The use of land plots in this case should be carried out "in accordance with federal laws" (part 7 of Article 36 [6]). Such an indication, however, does not clarify the situation, since neither the Water Code [11], nor the Land Code [12], nor other federal laws contain substantive norms in this regard. Therefore, in practice, the legal regime of such objects is determined by the planning of the territory, especially since the tendency to shift the emphasis to the institute of planning by reducing the role of urban 
planning (legal) zoning becomes obvious. At the same time, the legal regime for the use of adjacent land areas, defined by the urban planning regulations of a particular territorial zone from the Rules of Land Use and Development of the city of Moscow (https://www.mos.ru/mka/documents/pravila-zemlepolzovaniya-i-zastrojki-gorodamoskvy/) should certainly be taken into account.

The urban planning regulations should include restrictions on the use of land plots and capital construction projects in areas with special conditions for the use of the territory [7, 14]. However, due to the delay in the introduction of the necessary legal regulation, organizational and other reasons, the legal boundaries of many of these zones have not yet been established (information about them is not included in the state real estate cadastre). Accordingly, there are no de-jure restrictions. Objectively, the volume of such restrictions in relation to the development of the underground part of the territory is lower than on the surface of the earth. However, this is not always taken into account by federal legislation (see above for its improvement). For example, a significant part of the territory under consideration is included in the boundaries of the protected and protected zones of the Moscow Kremlin ensemble, on the territory of which, strictly speaking, both ground and underground construction is not provided. In the immediate vicinity of the Drainage Channel, there are also a number of other cultural heritage sites with their own protection zones, including places of interest and objects of archaeological heritage (https://www.mos.ru/dkn/documents/normativnye-pravovye-akty/). A similar situation with the legal establishment of some restrictions on construction takes place on the territory of water protection zones of the Drainage Channel, They are established in accordance with the Water Code "in order to prevent pollution, clogging, siltation of water bodies and depletion of their waters, as well as to preserve the habitat of aquatic biological resources and other objects of the animal and plant world" [11].

Some norms of civil, water and land legislation concerning the issues of monitoring (balance) of land, ownership of a Drainage channel, its land plot and their management may serve as a barrier to the implementation of the project. On the one hand, the canal itself as a watercourse (water body) is legally owned by the Russian Federation (federal property) [11]. On the other hand, in 2019, the Moscow Government provided for the placement of the Drainage Canal as an immovable linear structure on the state cadastral register with the cadastral number 77:01:0000000:3566 according to the "ownerless thing" model [13]. In our opinion, the correctness of such a procedure raises some doubts and should be further investigated (this opinion was shared in particular during oral discussions by some specialists of the Department of Agricultural and Environmental Legislation of the Institute of Legislation and Comparative Law under the Government of the Russian Federation). We are talking about some inconsistency of the norms of the Water Code on the exclusivity of federal ownership of the canal as a water object [11] and the norms of the Civil Code on the possibility of recognizing such a significant object as an ownerless thing [13]. It should be taken into account that the procedure for such recognition causes numerous disputes and court proceedings, and their subject is much less significant objects. We could not find any information about the delivery of the Drainage Canal as a water object for registration in the state water register, as well as information about it in the register of federal property. However, in any case, the right of ownership of the canal as an ownerless thing can be acquired by the city of Moscow solely on the basis of a court decision [13]. It should also be taken into account that, according to special legislation, channels are classified as hydraulic structures [14]. In this regard, the situation looks even more complicated, as the accumulated problems of systematization of information on water bodies and hydraulic structures in the city of Moscow remain unresolved.

If we consider land relations, then by virtue of both the Water Code and the Land Code, the land plot of the canal belongs to the federal lands of the water fund $[11,13]$. 
Accordingly, it is not the city of Moscow that disposes of such land plots, but the authorized federal executive authority. Moreover, on land covered by surface waters, the formation of land plots is not carried out at all (Article 102 [12]). At the same time, all lands used and intended for the development of settlements belong to the category of lands of settlements [12]. In this regard, the land of the water fund in the current balance of the land of the city of Moscow according to the reporting data is absent (https://base.garant.ru/375692/d8b01b57742d3a84cbe3048d71fc60a9/). However, the proper land plot of the canal is unlikely to be formed. At least, as part of the state real estate cadastre, we have not found any information about it (which once again indicates a possible violation of the fundamental principle of unity of the fate of land plots and objects firmly connected with them, according to which all such objects follow the fate of land plots [12]). In this case, the land plot will have to be formed from the land of non-delimited state ownership, and the type of its ownership will depend on the decision on the status of the Drainage Channel. If the canal is still a water object of federal ownership, then its land plot should also be classified as federal property. If, in the end, the canal is recognized as the property of the city of Moscow, then the land plot of the canal can be assigned to the city's property [12].

However, even if the relevant land plot of the canal is in federal ownership, it can be transferred free of charge to the public (state) property of the city of Moscow in accordance with Chapter V. 5 of the Land Code [12]. Similarly, executive and administrative functions in relation to a federal water body (watercourse) can be implemented by the city of Moscow within the framework of the powers transferred to it in the field of water relations (Article 26 [6]), which is relevant if registration of water use rights is required. However, it should be borne in mind that according to the article. 21 of the City Charter prohibits the alienation of land plots owned by Moscow and occupied by water bodies [15]. Therefore, the use of the land plot for the creation and operation of the Complex will be possible only on a lease basis, which, however, is quite usual for the practice of the capital.

In our opinion, it is possible to consider the model of artificial land plots on certain sections of the Complex proposed by the Draft Concept for dumping and subsequent improvement in the design of legal relations [16]. In this case, a draft plan for the relevant territory is prepared (it determines the types of permitted use of an artificial land plot), a contract and a draft permit for the creation of an artificial land plot. Such a permit, as well as a permit for the construction of the corresponding objects of the Complex, is issued by the executive authority of the city of Moscow. At the same time, the project documentation is subject to mandatory state environmental expertise, but if the conditions of the concluded contract are met, this land plot can already be transferred to private ownership.

\section{Conclusions}

Summarizing the preconditions for the realization of the Project concepts, among them we can mention the following (including compliance with SP 473).

1. The inadequate provision of Parking spaces (according to the Institute of General plan of Moscow a number of places organized storage of cars on the Central administrative district of the city is for living in the neighbourhood of $30 \%$ to arrive at the centre of the city - 40\%, https://moskva.bezformata.com/listnews/proveli-analiz-zagruzhennostiparkovochnogo/1493369/).

2. The lack of land areas near the Drainage Channel for new construction, creation of green and recreational areas, the need to ensure the protection of cultural heritage sites and the preservation of the historical environment, as well as the presence of relatively large population concentrations (Golden Island and other adjacent territories), congestion of the main land transport routes (paragraph 4.2. SP 473). 
3. Karst-suffusion processes may occur on the territory, which is noted, for example, in the draft Guidelines for the construction of underground structures for transport purposes in the conditions of karst-suffusion and landslide danger in the city of Moscow, compiled in 2020 with the participation of the author of this article (https://zakupki360.ru/tender/41032433). However, in general, the engineering and geological conditions of the territory are relatively favorable (point 4.3. SP 473).

4. The possibility of placing multifunctional underground objects and their complexes in the subroutine space (paragraphs 4.9., 4.10., 4.12., appendix B of SP 473).

Thus, the draft concept as a whole meets the general provisions of SP 473 SP 473, as well as the typology and general organization of the UUS, despite the fact that the specific requirements for the development of the sub-branch space of SP 473 does not contain (this circumstance, together with other shortcomings, implies a corresponding revision of this document [5]).

In general, the focus of the Draft Concept corresponds to the current strategic direction of sustainable spatial development, as well as such basic provisions of the approved General Plan of Moscow [5] in terms of the development of UUS as:

- preservation of the characteristics of the historical layout and development, as well as the development of public spaces and green areas;

- ensuring the availability of service facilities, places of employment, places of storage of vehicles;

- formation of a comfortable environment in the areas of concentration of the daily population of Moscow: in the system of the citywide center and in tourist and recreational areas.

The method of subsurface spatial development itself has an innovative character, responding to the directive directions of the development of the national economy and global trends (the "Amphora" project in Amsterdam, etc.). The proposed project can certainly attract investment interest from both foreign and Russian companies, including suppliers of equipment and building structures. This will allow the project to be implemented on the model of public-private partnership.

At the same time, it is advisable to further work out the noted problematic points concerning the implementation of the Draft Concept and the proposed possible options for reducing legal, reputational and other risks with unconditional compliance with federal legislative requirements. In particular, the issues of land plot formation and its cadastral registration, in our opinion, require special additional analysis.

At the same time, it should be clearly understood that before making appropriate changes and additions to the federal legislation, there are a number of gaps, conflicts and unjustified legal requirements (for example, in terms of the need to obtain a license for the use of mineral resources). Up to this point, the requirements of both SP 473 and SP 473, as well as some other standardization documents related to the development of UUS, can also not be fully applied [5].

Despite the statement of the NIIOSP specialists that operation of the Complex will not cause negative impacts on the river system network and will not result in restrictions on river traffic, acquire the necessary approvals from the relevant authorities and services of the Federal Ministry of natural resources (see for example, above about the reasons of failure of competition 15 pallet car parks in the riverbed of the Moscow river).

It is also advisable to take into account of successful referential world of urban planning practice, in particular to consider that underground space is a resource and other services (geo-energy, geo-materials, groundwater, etc.) for example, on the model of "Deep city" [5].

Regarding the implementation of the above-mentioned work according to the "urban capacity", it can be supported with additional research it issues, are considered in the 
article-oriented and the format of relevant materials justifying documents (documentation) urban design. In general, such work, having an interdisciplinary nature, fully corresponds to one of the three sections of fundamental and exploratory scientific research in the field of urban planning for 2021-2030 (http://government.ru/news/41288/).

Being itself a new and sustainable direction for development of the underflow space in Moscow, of course, it must be strongly supported by another based on the fact that it is extremely important for example to St.-Petersburg and some other major Russian cities as a way for sustainable spatial development of their Central parts. In this regard, the implementation of the considered development of the UUS is considered as a kind of pilot project.

It should also be emphasized that if the potential of the UUS is used comprehensively and regulatory risks are removed, the implementation of the project can have a significant environmental effect (improving the quality standards of the urban environment, additional landscaping, creating new recreational areas, improving the safety and level of use of waterways, holding mass environmental events, reducing harmful emissions, noise, etc.), development of tourism, culture, sports infrastructure, preservation of architectural and historical heritage, unique recreation and entertainment options, new jobs), and long-term economic effects (provided that calculations are applied in the context of the entire life cycle and the inclusion of public-private partnership mechanisms).

\section{References}

1. Law of the City of Moscow of 05.05.2010 №. 17 «On the General Plan of the City of Moscow»

2. Resolution of the Government of Moscow of 03.10.2011 № 460-PP «On approval of the State program of the City of Moscow «Urban Planning Policy»»

3. V. M. Ulitsky, Kh. A Dzhantimirov, I. V. Kolybin, Transport of the Russian Federation 4 (47), 46-50 (2013) eLIBRARY ID: 20406573

4. Kh. A. Dzhantimirov, V A Kitaykin, Herald NIC Building 10, 36-42 (2014) eLIBRARY ID: 27297028

5. V. Belyaev, Characteristics and problems of the standardization of urban design in the development of urban underground space In: E3S Web of Conferences 164, 04034 (2020) https://doi.org/10.1051/e3sconf/202016404034

6. «Urban Planning Code of the Russian Federation», № 190-FZ (2004)

7. Moscow Law of 25.06.2008 № 28 «Urban Planning Code of the City of Moscow»

8. Resolution of the Government of Moscow of 23.12.2015 № 945-PP «On approval of regional standards of urban planning design of the city of Moscow in the field of transport, highways of regional or inter-municipal significance»

9. E.K. Trutnev, Urban regulation: Legal support of urban planning activities: alternative models of legislation and a program for correcting its errors (Moscow, Institute of City Economics, 2019) ISBN 978-5-8130-0185-7

10. Resolution of the Government of Moscow of 30.04.2019 № 449-PP «On approval of the Regulations on the composition, procedure for preparation, approval and submission for approval of territory planning projects in the city of Moscow»

11. «Water Code of the Russian Federation», № 74-FZ (2006)

12. «Land Code of the Russian Federation», № 136-FZ (2001)

13. "«Civil code of the Russian Federation» (part one), № 51-FZ (1994) 
14. Federal Law №. 117-FZ of 21.07.1997 «On the Safety of Hydraulic Structures»

15. The Law of Moscow of 28.06.1995 «Charter of the City of Moscow»

16. Federal Law №. 246-FZ of 19.07.2011 «On Artificial Land Plots Created on Water Bodies that are in Federal Ownership and on Amendments to Certain Legislative Acts of the Russian Federation» 